\title{
A Review of Recent Experimental and Theoretical Research of Dew Point Evaporative Coolers
}

\author{
Prashant Patunkar $^{{ }^{*}}$, Sunil Dingare ${ }^{2}$, and Virendra Bhojwani ${ }^{1}$ \\ ${ }^{1}$ Department of Mechanical Engineering, MIT School of Engineering, Pune (India) \\ ${ }^{2}$ Department of Aerospace Engineering, MIT School of Engineering, Pune (India)
}

\begin{abstract}
Evaporative cooling is one of the techniques to lower the ambient air temperature according to the requirements. The technique includes the injection of moisture in the coming air, thus increasing its specific humidity. This technique can cool the air up to wet bulb temperature of the incoming air. In the recent past, the techniques are developed to lower the temperature of air without addition of moisture in the incoming air. These techniques demonstrate that the incoming air temperature can be approached near the dew point temperature of the incoming air. The present paper essentially focuses on the recent theoretical and experimental research of dew point evaporative coolers. Different flow configurations of heat exchange mediums, optimization of geometrical parameters, performance parameters (wet bulb and dew point effectiveness), energy efficiency ratio and energy saving potential are the key elements to study the prospects of dew point evaporative coolers over the conventional refrigeration systems operated by mechanical means. Dew point evaporative cooling technology is environmental friendly and has the potential in reducing the impact on earth due to global warming.
\end{abstract}

\section{INTRODUCTION}

The usage of conventional air conditioning system for residential, commercial and industrial applications contributes to the bulk consumption of electrical units. The consumption trends across world wide leads to climate change, which may further worsen the situations in the coming future. Therefore, it is the need of the hour to make available better options for the cooling pusposes. Evaporative cooling (direct and in direct) is considered an energy efficient and enivormental friendly technique. Direct evaporative cooling includes mixing of two streams, i.e. air and water, whereas in direct evaporative cooling both these streams are separated by heat exchange surface with wet and dry channels.

\section{EXPERIMENTAL RESEARCH OF DEW POINT COOLERS}

Liu et.al [1] investigated experimentally and theoretically the refrigeration behaviour of a highly efficient dew point evaporative cooler using most effective air and water flow arrangements. Different results obtained from the experiments reported the improvement of $29.3 \%$ in the cooler wet bulb efficiency. Increase in COP achieved by slightly greater than one third in contrast to the commercially available dew point air cooler of equal capacity. On account of usage of corrugated plates helped to achieve the cooling efficiency more that $10 \%$ as compared to flat plates. Further the refrigeration efficiency of dew point cooler in original configuration is only $62-67 \%$ that of a dew point evaporative cooler as compared to counter flow configuration. The paper reported that the refrigeration performance can be enhanced by enlarging the geometrical parameters such as length of the channel along with the air entrance length and minimizing the width and gap of the channel within a acceptable limit. The experimental set up designed with the corrugated plates is shown in Fig. 1.

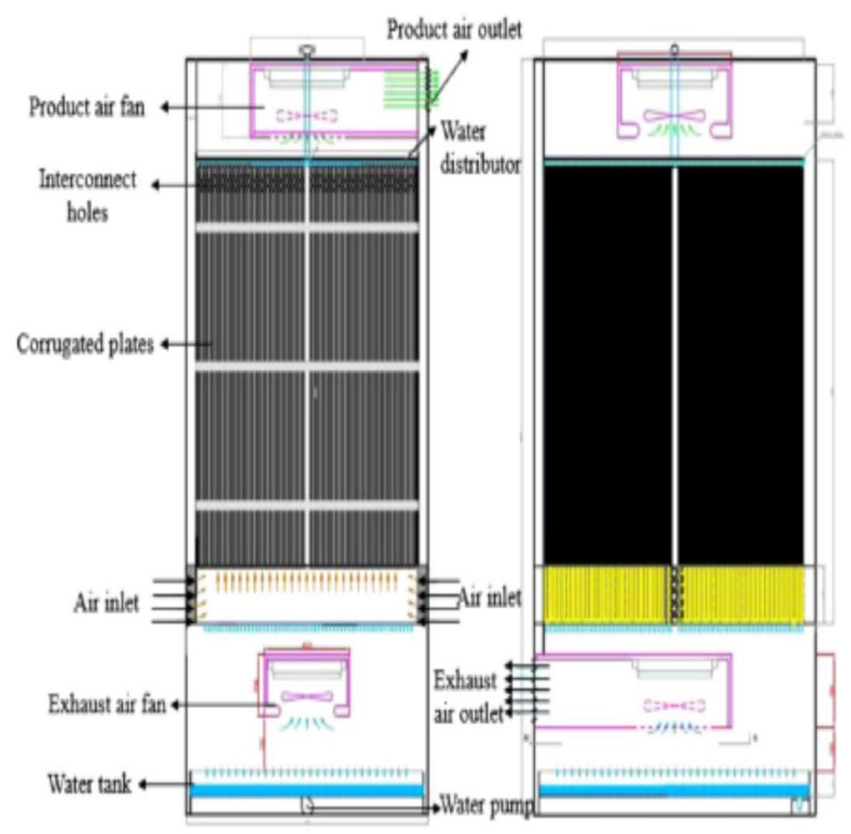

Fig. 1 Layout for Dew point evaporative cooler [1]

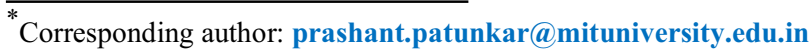


The detailed geometrical parameters of the prototype used are mentioned in Table 1.

Table 1. Different geometrical dimensions for prototype [1]

\begin{tabular}{|c|c|}
\hline Geometrical Dimension & Value \\
\hline Length of the channel & $1.05 \mathrm{~m}$ \\
\hline Width of the channel & $0.716 \mathrm{~m}$ \\
\hline Channel spacing & $4.3 \mathrm{~mm}$ \\
\hline Air entrance length & $175 \mathrm{~mm}$ \\
\hline Dry channels utilized & 117 \\
\hline Wet channels utilized & 117 \\
\hline
\end{tabular}

The comparison of prototype and M30 cooler is mentioned in Table 2.

Table 2 Difference between prototype and M30 [1]

\begin{tabular}{|l|l|l|}
\hline \multicolumn{1}{|c|}{ Type of arrangement } & \multicolumn{1}{|c|}{ M30 } & Prototype \\
\hline $\begin{array}{l}\text { Preliminary air flow rate } \\
\left(\mathrm{m}^{3} / \mathrm{h}\right)\end{array}$ & 4522 & 2719 \\
\hline $\begin{array}{l}\text { Actual air flow rate } \\
\left(\mathrm{m}^{3} / \mathrm{h}\right)\end{array}$ & 3349 & 2363 \\
\hline Flow ratio & 1615 & 1188 \\
& 0.523 & 1223 \\
\hline Inlet air dry bulb & 0.482 & 0.437 \\
temperature $\left({ }^{0} \mathrm{C}\right)$ & 37.78 & 0.445 \\
\hline Inlet air wet bulb & 21.11 & 38.6 \\
temperature $\left({ }^{0} \mathrm{C}\right)$ & 18.33 & 20.28 \\
\hline Product air temperature & 22 & 17.8 \\
$\left({ }^{0} \mathrm{C}\right)$ & 20.94 & 20.9 \\
\hline Cooling capacity (kW) & 11.77 & 10.83 \\
\hline Wet bulb efficiency & 10.08 & 9.65 \\
\hline COP & $94.5 \%$ & $114 \%$ \\
& $88.2 \%$ & $107 \%$ \\
\hline
\end{tabular}

The tests were carried in constant temperature and humidity environment. The experimental results obtained the wet bulb efficiency of $114 \%$ and dew point efficiency of $68.4 \%$, refrigeration effect of 10.8 Watts and highest coefficient of performance of 42.8 for standard operating conditions.

Frank Bruno [2] presented the findings achieved after testing a prototype cooler operated in commercial as well as residential purposes over varied sets of atmospheric conditions. Two different coolers operated at other sites were tested for the purpose to evaluate the output characteristics of the devices working in commercial as well as residential applications in the presence of varied atmospheric conditions. For the commercial application the device could cool the air from more than $40^{\circ} \mathrm{C}$ to nearly $15^{\circ} \mathrm{C}$. The total data was obtained for the period of 44 days where in the daily average ambient air temperature ranged between $22.5^{\circ} \mathrm{C}$ and $40.3^{\circ} \mathrm{C}$. The daily average humidity ranged between $10 \%$ and $55 \%$. Fig. 2 shows the variation of Energy efficiency ratio with the difference of dry bulb and dew point temperature.

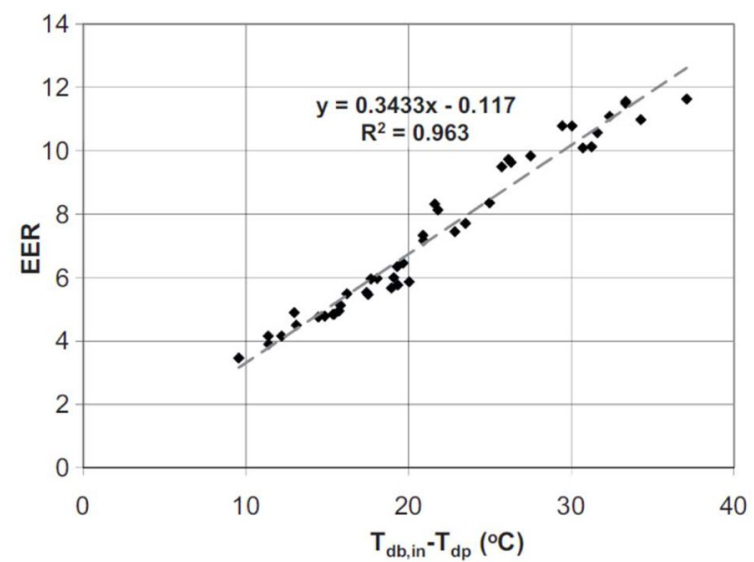

Fig.2 Variation of energy efficiency ratio with difference between dry bulb and dew point temperature of atmospheric air (commercial building) [2]

The linear relationship was obtained between the energy efficiency ratio and difference between dry bulb inlet and dew point outlet temperature. The daily average wet bulb and dew point effectiveness of the prototype with respect to dew point temperature is shown in Fig. 3.

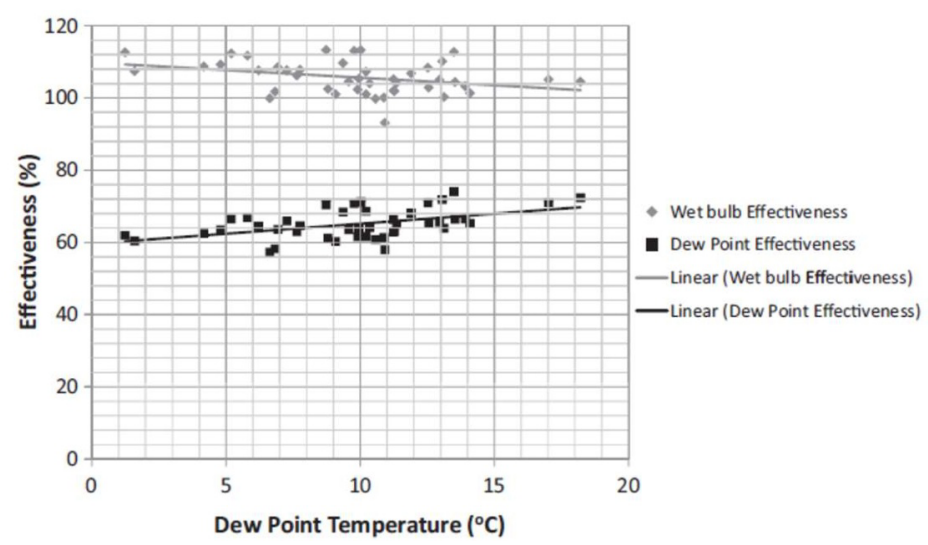

Fig.3 Variation of wet bulb and dew point effectivenesses with dew point temperature (commercial application) [2]

Average values for wet bulb and dew point effectiveness obtained were $106 \%$ and $65 \%$ respectively for the commercial application. Fig. 4 shows the variation of energy efficiency ratio with respect to dew point temperature and Fig. 5 shows the daily average wet bulb 
and dew point effectivenesses with respect to atmospheric dew point temperature.

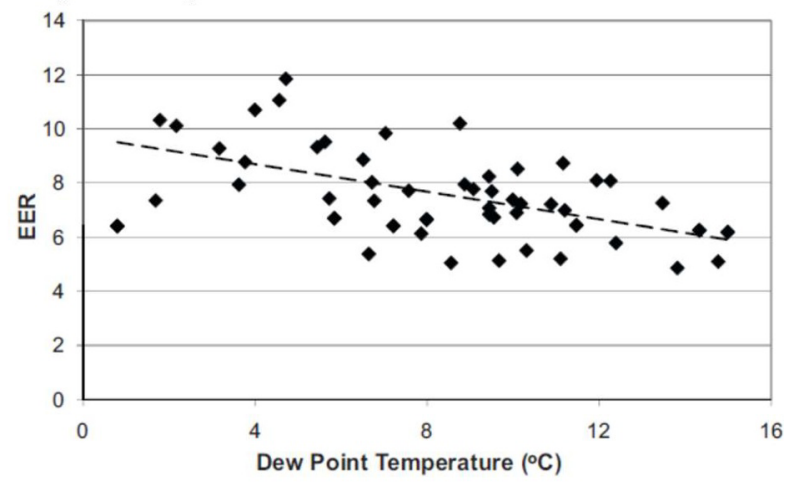

Fig.4 Variation of energy efficiency ratio with dew point temperature of atmospheric air (household application) [2]

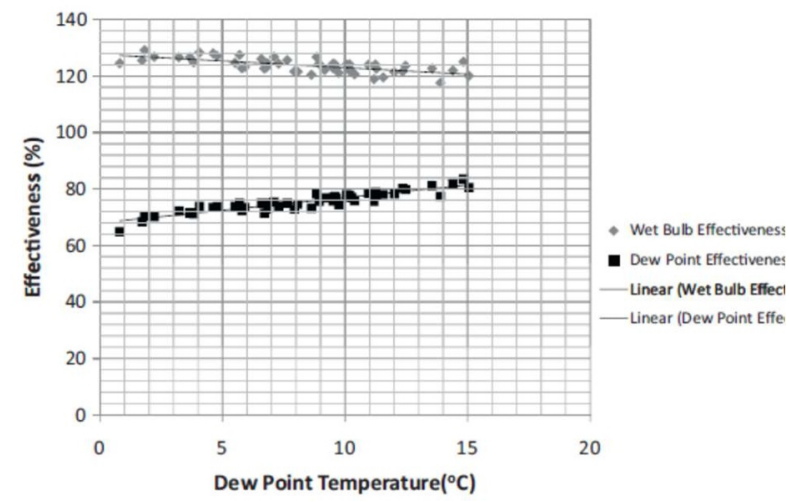

Fig.5 Variation of Wet bulb dew point effectivenesses with dew point temperature [2]

The EER observed to increase as the dew point temperature reduces. The average wet bulb and dew point effectivenesses obtained were $124 \%$ and $75 \%$ respectively for residential installation. The analysis was also performed to study the potential energy saving from the cooler for commercial building application. The empirical correlation was developed between the energy efficiency ratio, condenser temperature and air temperature on the evaporator. The results were obtained for the configuration of counter flow indirect evaporative cooler for commercial as well as household installations. The yearly energy saving was proposed in the range of 52 and $56 \%$.

The thermodynamic performance of a innovative device as cooler was investigated by Jia et.al. [3] A mini size counter cross flow device coated with nylon fibers over wet channel portion was investigated. The significance of the operational parameters on thermodynamic performance was investigated. The findings obtained indicated that, device applied with coating of nylon fibers delivered enhanced cooling output. The combination of polystyrene nylon fibre delivered the dew point efffectiveness of $46.7 \%$ to $78.6 \%$. The effectiveness of this combination was in good agreement with counter flow evaporative cooler and higher than that of cross flow evaporative devices. The schematics of the arrangement is shown in Fig.6.

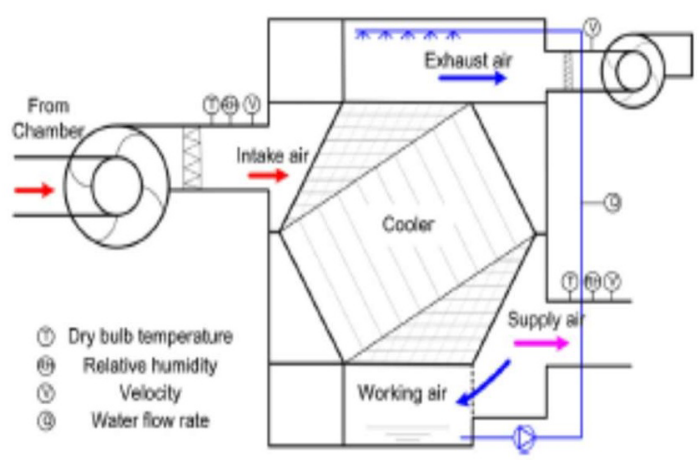

Fig. 6 Arrangement for experimental apparatus [3]

Experimental apparatus consists of an air distribution arrangement, a water circulation arrangement along with arrangement for heat transfer. The test set up operated with supply air flow rate and working -to-intake air ratio (WIR) at $85 \mathrm{~m}^{3} /$ hour and 0.4 respectively. The inlet air temperature was adjusted to $29.5^{\circ} \mathrm{C}, 32.5^{\circ} \mathrm{C}$ and $35.5^{\circ} \mathrm{C}$ and the specific humidity of $16 \mathrm{~g} / \mathrm{kg}$. The variation of dew point effectiveness with respect to intake air temperature for different wet surface materials is shown in Fig.7.

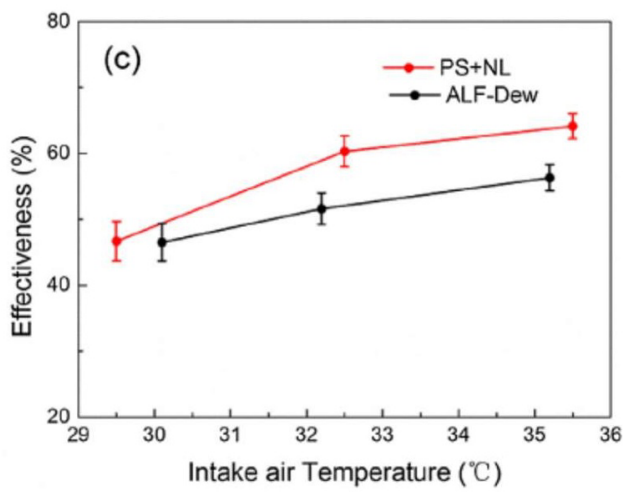

Fig.7 Dew point effectiveness versus intake air temperature for various substances [3]

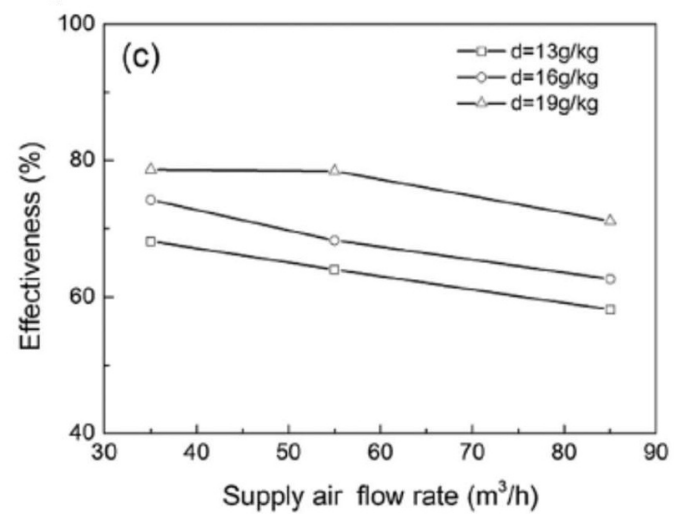

Fig. 8. Variation of effectiveness with supply air flow rate [3] 
The effect of intake air flow rate on the dew point effectiveness is shown in Fig. 8. It is observed that the dew point effectiveness of the cooler decreases slightly with enhanced intake air flow rate which may be due lower contact period of air and wet surface due to increased air flow rate. The parameters such as air temperature, relative humidity and air velocity were examined. Dew point effectiveness was determined mathematically. The impact of wet surface material, intake air flow rate, work to intake air ratio (WIR), air intake temperature, intake air humidity on the thermal performance of the device was analysed. The suggested device showed the capability to make it compact and weight of the device with simultaneously constant volume of air.

Lin et.al. [4] designed and engineered a counter flow dew point evaporative cooler and the assembled experimental set up is shown in Fig.9. The size of device has dimensions as $0.8 \mathrm{~m} \times 0.18 \mathrm{~m} \times 4.0 \mathrm{~m}(\mathrm{~L} \mathrm{x} \mathrm{W} \mathrm{x} \mathrm{H})$.

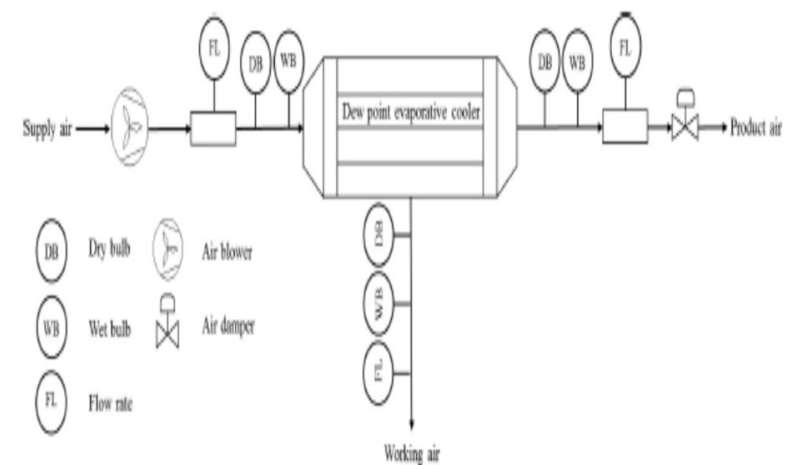

Fig. 9 Experimental set up for the device [4]

The testing parameters for the set up are mentioned in Table 3.

Table 3 Testing parameters for the set up [4]

\begin{tabular}{|l|c|c|}
\hline Parameter & value & Range \\
\hline Length of the Channel & $0.8 \mathrm{~m}$ & - \\
\hline Width of the Channel & $0.18 \mathrm{~m}$ & - \\
\hline Height of the Channel & $4.0 \mathrm{~mm}$ & - \\
\hline Intake air temperature & $32.5^{0} \mathrm{C}$ & $27.2-40.3$ \\
\hline $\begin{array}{l}\text { Intake air moisture } \\
\text { content }\end{array}$ & $10.0 \mathrm{~g} / \mathrm{kg}$ & $9.8-19.6$ \\
\hline Intake air velocity & $2.0 \mathrm{~m} / \mathrm{s}$ & $1.9-2.1$ \\
\hline Operating air ratio & 0.33 & $0.31-0.33$ \\
\hline
\end{tabular}

Pakari and S. Ghani [5] developed and tested a prototype of cooling system with the prime objective for validation of the numerical model of the device. Fig. 10 shows a schematic of the device. The trials were taken on the device by regulating the intake air temperature, intake air moisture content, and intake air velocity. The regulation of extraction ratio was carried with the help of standby blower fixed at the outlet of the wet channel.

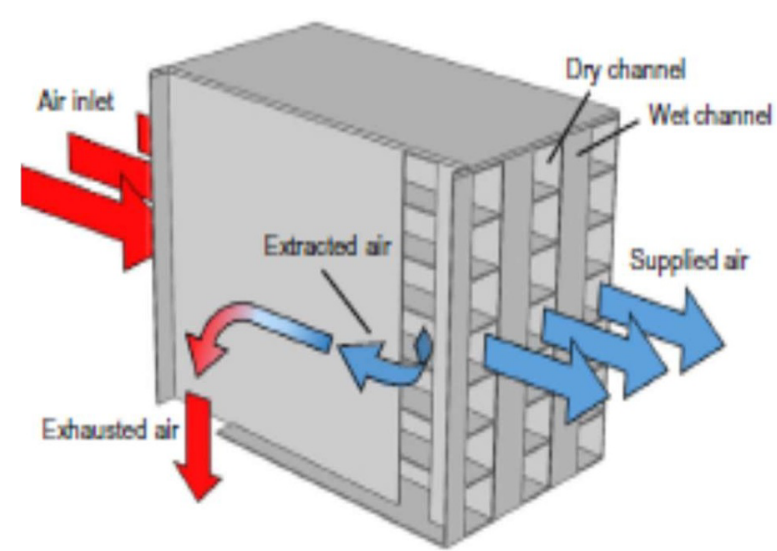

Fig. 10 Flow arrangement for the test device [5]

The technical specifications of the experimental set are mentioned in Table 4.

Table 4. Dimensional parameters for test device [5]

\begin{tabular}{|l|c|}
\hline Parameter & Value \\
\hline Dry channel thickness & $2 \mathrm{~mm}$ \\
\hline Wet channel thickness & $2 \mathrm{~mm}$ \\
\hline Length of the channel & $0.5 \mathrm{~m}$ \\
\hline Height of the channel & $0.3 \mathrm{~m}$ \\
\hline Heat exchanger thickness & $0.22 \mathrm{~m}$ \\
\hline Thickness of plate & $0.2 \mathrm{~mm}$ \\
\hline Paper thickness & $0.15 \mathrm{~mm}$ \\
\hline
\end{tabular}

Fig. 11 shows layout of the test device.

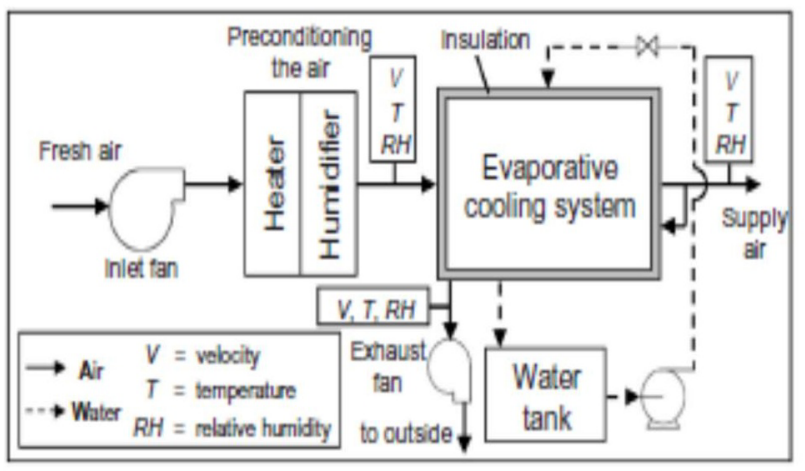

Fig. 11 Layout for the test device [5]

The exit temperature and moisture content for the device were tested in 3 cities for a year and changes of monthwise exit air temperature and moisture content obtained between $30^{\circ} \mathrm{C}$ and 20 to $70 \%$ respectively.

THEORETICAL RESEARCH OF DEW POINT COOLERS 
The fundamental analysis of heat and mass transfer for the counter-flow dew point evaporative cooler was investigated by Lin et.al. [4]. The simulation and experimental analysis has been done for the objective of validating at the preliminery stage, the convection and mass transfer phenomenon of the device. The value of the convection heat and mass transfer coefficients were obtained by log mean temperature/humidity difference technique. The simulation of heat and mass transfer response of the device has been analysed with the help of 2 dimensional model. Various parameters such as product air temperature, convection heat and mass transfer coefficients and dimensionless numbers were simulated with various parameters as shown in Table 5.

Table 5 Simulation parameters for the device [4]

\begin{tabular}{|l|c|c|}
\hline Parameter & Value & Range \\
\hline $\begin{array}{l}\text { Length of the channel } \\
(\mathrm{m})\end{array}$ & 0.8 & $0.5-1.2$ \\
\hline $\begin{array}{l}\text { Thickness of plate and } \\
\text { film }(\mathrm{mm})\end{array}$ & 0.25 & $0.15-0.55$ \\
\hline Channel height $(\mathrm{mm})$ & 4.0 & $2.0-6.0$ \\
\hline $\begin{array}{l}\text { Supply air temperature } \\
\left({ }^{0} \mathrm{C}\right)\end{array}$ & 30 & $27.5-40.0$ \\
\hline Inlet air moisture $(\mathrm{g} / \mathrm{kg})$ & 13.3 & $8.0-18.0$ \\
\hline Inlet air velocity $(\mathrm{m} / \mathrm{s})$ & 2.0 & $1.0-3.0$ \\
\hline Working air ratio & 0.33 & $0.1-0.9$ \\
\hline
\end{tabular}

The study also revealed that factors which made significant impact on the heat and mass transfer performance were $\mathrm{Re}_{\mathrm{D}}, \mathrm{H} / \mathrm{L}, \delta / \mathrm{H}$ and $\pi$. A 2 dimensional CFD model of the device is obtained with fundamental balance mathematical relations. The theoretical results obtained may be utilized for different real life examples. Sohani et.al. [6] proposed an optimization methodology to boost improving potential of devices. The system output was modeled throughout the year and then, hour basis readings for inlet parameters was used and diversified optimization was carried out after alternate hour. The objective functions focussed were cost of running, coefficient of performance and rate of water flow. The hour, month and yearwise findings were analyzed and put forth. Based upon four different cliamatic conditions investgated, the results showed substantially enhanced scope for the hour basis optimization technique to escalate the objective functions 18.7, 19.6 and $36.2 \%$ on an average. The hourly optimization strategy (HOS) is proposed, which was so far untapped for the improvement of potential of the device.

Akhlaghi et.al.[7] develpoed a regression model to predict the thermodynamic performance of the device. The proposed model helps to establish the relationship of various parameters with operating parameters such as, flow and dimensional parameters as mentioned in Table 6.
Table 6 Geometrical and water parameters for the proposed model [7]

\begin{tabular}{|c|c|}
\hline Parameter & Value \\
\hline Length of the channel & $1.2 \mathrm{~m}$ \\
\hline Width of the channel & $0.348 \mathrm{~m}$ \\
\hline Pitch & $0.005 \mathrm{~m}$ \\
\hline Stacks & 200 \\
\hline Water temperature & $16^{0} \mathrm{C}$ \\
\hline Water circulation rate & $18 \mathrm{~kg} / \mathrm{s}$ \\
\hline
\end{tabular}

The operational parameters taken into consideration are, inlet air conditions, which includes moisture content, flow rate in addition to working air fraction over the inlet air, where as refrigeration capacity, COP, pressure drop, dew point, wet bulb effectiveness were considered as operating conditions. The gemoetric characteristics selected are height of the channel, its interval and number of stacks in heat and mass exchange. The selected $8^{\text {th }}$ degree model produced highest comparative difference for the refrigeration capacity, COP, pressure drop, dew point along with wet bulb effectivenesses were $6.1 \%, 7.54 \%$, $0.07 \%, 3.54 \%$ and $2.53 \%$ respectively. The introduction of the MPR into dew point cooler technique imparts crucial significance for characterization of the specific feature to device. The proposed polynomial has the potential of further extension to determine optimised dimensional as well as flow characteristics correlated with the device not only for varied climatic but also for the different operating situations.

Pakari and S. Ghani [5] developed the regression models so as to predict the out put characteristics, help for the design and optimization of the device. The detailed analysis includes regression models, analytical equations, which in turn correlates various inlet conditions, such as working and dimensional terms and properly chosen exit performances of the device by applying numerical tests in addition to response surface technique. The parameters taken into consideration are temperature of the intake air, moisture content, air intake velocity along with extraction ratio. The dimensional terms include length and width of refrigeration stsyem's passages.

Various results obtained from the numerical model and experimental measurements for the outlet air temperature are shown in Fig. 12. The results match within the range of $10 \%$. The average discrepency observed has been about $5.2 \%$. The output behaviour parameters taken into consideration are temperature of the air, moisture content in addition to wet bulb efficiency.

The proposed regression model helps to analyse the exit parameters for the refrigeration systems in the absence of any priority for the solution differential equations. 


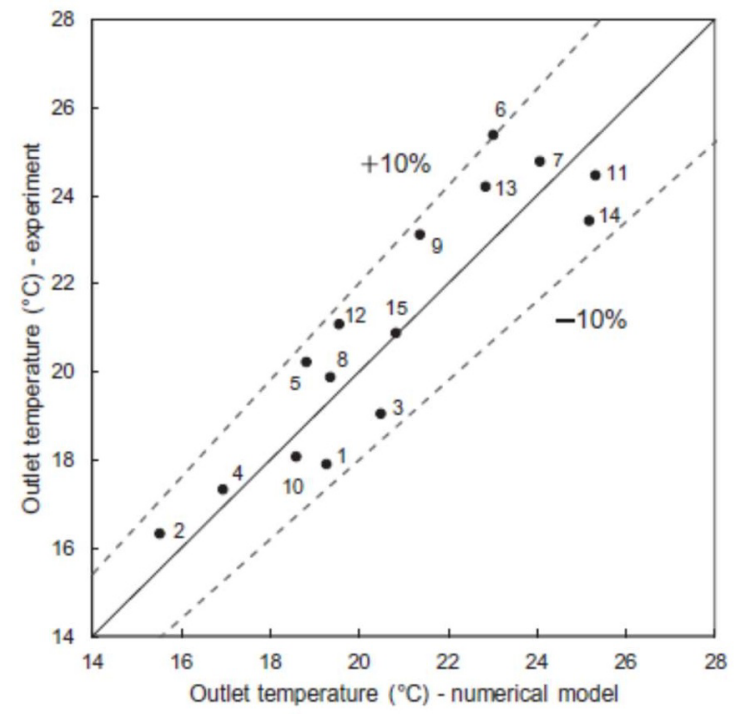

Fig.12 Variation of the trend in exit temperatures obtained by numerical and experimental technique [5]

The regression models possesses resonable accuracy which turns to be beneficial for the application in energy oriented codes for the thermodynamic response projection of the cooling devices.

Liu et.al. [8] proposed the numerical model which was subsquently cross checked experimentally with the similar results obtained from various investigations. The significance of the model extended to investigate the different working parameters such as intake discharge of air, air ratio, intake temperature of water, discharge of water along with temperature and moisture content for the intake air related to refrigeration capacity on the modified construction of the device. The proposed numerical model achieves similar results with experimental results obtained in contrast to the various researchers with variation of less than $5 \%$ obtained by experimental and numerical techniques.

Ali Pakari and Saud Ghani [9] studied the thermodynamic behaviour of refrigeration device by numerical as well as experimental technique. The proposed one dimensional model of heat and mass exchange for the cooler is analysed and compared with developed three dimensional model. Findings obtained from experimental set up achieved the wet bulb efficiency for refrigeration cycle attained figures close to $125 \%$. Further investigation revealed that, one dimensional model proposes relatively less exit temperatures nearly $1.86 \%$ as compared with three dimensional model. The proposed exit temperatures for refrigeration cycle obtained by both models validates the experimental findings close to $10 \%$ and $8.5 \%$ respectively. One dimensional model appropriately indicates thermodynamic response for refrigeration cycle on account of faster computing speed and available facilities in contrast to three dimensional model. From the various factors considered, the extraction ratio makes the significantly appreciable impact on the wet bulb efficiency. Wet bulb efficiency is directly proportional to the extraction ratio.

\section{CONCLUSION}

The present paper reviews on the recent experimental and theoretical research of dew-point evaporative coolers. Such coolers have the significant energy saving potential for residential and commercial applications. The performance of the dew point evaporative cooler is governed significantly by operational and geometrical parameters. Those parameters can be further used for the experimental investigations and numerical validation for a small capacity domestic air conditioning system based on the usage of non-conventional energy for the year round climate.

\section{REFERENCES}

1. Y. Liu, Y.G. Akhlaghi, X. Zhao, J. Li, Experimental and numerical investigation of a high-efficiency dewpoint evaporative cooler, Energy \& Bulidings 197 (2019) 120-130.

2. F. Bruno, On-site experimental testing of a novel dew point evaporative cooler, Energy \& Buildings 43 (2011) 3475-3483.

3. L. Jia, J. Liu, C. Wong, X. Cao, Z. Zhang, Study of the thermal performance of a novel dew point evaporative cooler, Applied Thermal Engineering 160 (2019) 114069.

4. J. Lin, D.T. Bui, R. Wang, K.J. Chua, On the fundamental heat and mass transfer analysis of the counter-flow dew point evaporative cooler, Applied Energy 217 (2018) 126-142.

5. A. Pakari, S. Ghani, Regression models for prediction of counter flow dew point evaporative cooling systems, Energy Conversion and Management 185 (2019) 562-573.

6. A. Sohani, H. Sayyaadi, M. Zeraatpisheh, Optimization strategy by a general approach to enhance improving potential of dew point evaporative coolers, Energy Conservation and Management 188 (2019) 177-213.

7. Y.G. Akhlaghi, X. Ma, X. Zhao, S. Shittu, A statistical model for dew point air cooler based on the multiple polynomial regression approach, Energy 181 (2019) 868-881.

8. Y. Liu, J.M. Li, X. Yang, X. Zhao, Two-dimensional numerical study of heat and mass exchanger for a dew-point evaporative cooler, Energy 168 (2019) 975-988.

9. A. Pakari, S. Ghani, Comparison of $1 \mathrm{D}$ and $3 \mathrm{D}$ heat and mass transfer models of a counter flow dew point evaporative cooling system: Numerical and experimental study, International Journal of Refrigeration 99 (2019) 114-125. 